\title{
Unique Tracheal Fluid MicroRNA Signature Predicts Response to FETO in Patients With Congenital Diaphragmatic Hernia
}

\author{
Patricia Pereira-Terra, ${ }^{* \dagger}$ Jan A. Deprest, MD, PhD, $\ddagger$ Ramin Kholdebarin, MD, MSc, ${ }^{*}$ Naghmeh Khoshgoo, ${ }^{*}$ \\ Philip DeKoninck, MD, PhD, $\ddagger$ Anne A. Boerema-De Munck, § Jinxia Wang, $\uparrow$ Fuqin Zhu, ${ }^{*}$ Robbert J. Rottier, PhD, $\S$ \\ Barbara M. Iwasiow, MSc, ${ }^{*}$ Jorge Correia-Pinto, MD, PhD, † Dick Tibboel, MD, PhD, § Martin Post, DVM, PhD, $\uparrow$ \\ and Richard Keijzer, $M D, P h D, M S c^{*}$
}

\begin{abstract}
Objective and Background: Our objective was to determine the fetal in vivo microRNA signature in hypoplastic lungs of human fetuses with severe isolated congenital diaphragmatic hernia $(\mathrm{CDH})$ and changes in tracheal and amniotic fluid of fetuses undergoing fetoscopic endoluminal tracheal occlusion (FETO) to reverse severe lung hypoplasia due to $\mathrm{CDH}$.

Methods: We profiled microRNA expression in prenatal human lungs by microarray analysis. We then validated this signature with real-time quantitative polymerase chain reaction in tracheal and amniotic fluid of $\mathrm{CDH}$ patients undergoing FETO. We further explored the role of miR-200b using semiquantitative in situ hybridization and immunohistochemistry for TGF- $\beta 2$ in postnatal lung sections. We investigated miR-200b effects on TGF- $\beta$ signaling using a SMAD-luciferase reporter assay and Western blotting for phosphoSMAD2/3 and ZEB-2 in cultures of human bronchial epithelial cells.

Results: CDH lungs display an increased expression of 2 microRNAs: miR$200 \mathrm{~b}$ and miR-10a as compared to control lungs. Fetuses undergoing FETO display increased miR-200 expression in their tracheal fluid at the time of balloon removal. Future survivors of FETO display significantly higher miR200 expression than those with a limited response. miR-200b was expressed in bronchial epithelial cells and vascular endothelial cells. TGF- $\beta 2$ expression was lower in CDH lungs. miR-200b inhibited TGF- $\beta$-induced SMAD signaling in cultures of human bronchial epithelial cells.
\end{abstract}

From the * Departments of Surgery, Division of Pediatric Surgery, Pediatrics \& Child Health and Physiology \& Pathophysiology (adjunct), University of Manitoba and Biology of Breathing Theme, Manitoba Institute of Child Health, Winnipeg, Manitoba, Canada; $\nmid$ Life and Health Sciences Research Institute/3B'sPT Government Associate Laboratory, Braga/Guimarães, Portugal and Department of Pediatric Surgery, Hospital de Braga, Braga, Portugal; $\ddagger$ Clinical Department of Obstetrics and Gynaecology, University Hospitals Leuven and Academic Department Development and Regeneration, Organ System Cluster, KU Leuven, Leuven, Belgium; §Department of Pediatric Surgery, Erasmus MC-Sophia, Rotterdam, The Netherlands; and $₫$ Program in Physiology and Experimental Medicine, Hospital for Sick Children, Toronto, Ontario, Canada.

Disclosure: Supported by the Canadian Institutes of Health Research (MOP-77751), Canada; Erasmus MC fellowship Rotterdam, The Netherlands; Michaël-Van Vloten Foundation, Rotterdam, The Netherlands; Manitoba Medical Services Foundation; Manitoba Institute of Child Health; Molly Towell Perinatal Research Foundation; Department of Surgery GFT Surgeons; and Thorlakson Foundation. R.K. is the recipient of a Career Development Award from the Canadian Child Health Clinician Scientist Program and a New Investigator Salary Award from the Canadian Institutes of Health Research, Manitoba Lung Association, and the Manitoba Institute of Child Health. J.D.P. is a clinical scientist funded by the Fonds voor Wetenschappelijk Onderzoek Vlaanderen (1.8012.07). P.D.K. is funded by the European Commission (IndustriaAcademia Partnership via www.endovv.com; PIAP-GA-2009-251356). The authors declare there are no conflicts of interest.

Supplemental digital content is available for this article. Direct URL citations appear in the printed text and are provided in the HTML and PDF versions of this article on the journal's Web site (www.annalsofsurgery.com).

Reprints: Richard Keijzer, MD, PhD, MSc, Thorlakson Chair in Surgical Research, AE402-840 Sherbrook Street, Winnipeg, Manitoba, Canada, R3A 1R9. E-mail: richardkeijzer@gmail.com.

Copyright (C) 2015 Wolters Kluwer Health, Inc. All rights reserved.

ISSN: 0003-4932/15/00000-0001

DOI: $10.1097 /$ SLA.0000000000001054
Conclusions: Human fetal hypoplastic $\mathrm{CDH}$ lungs have a specific miR200/miR-10a signature. Survival after FETO is associated with increased miR-200 family expression. miR-200b overexpression in CDH lungs results in decreased TGF- $\beta / \mathrm{SMAD}$ signaling.

Keywords: congenital diaphragmatic hernia, miR-10a, miR-200, pulmonary hypoplasia, TGF- $\beta$ signaling, tracheal occlusion

(Ann Surg 2015;00:1-11)

$\mathrm{C}_{\mathrm{f}}$ ongenital diaphragmatic hernia (CDH) is a developmental defect of the diaphragm, allowing herniation of abdominal viscera into the chest. It occurs in 1 in 2000 to 3000 live births. ${ }^{1}$ Although postnatal treatment has become more standardized, substantial morbidity and mortality result from the associated pulmonary hypoplasia and abnormal vascular development of the newborn. A subset of fetuses with liver herniation and a smaller lung size, represented by an observed overexpected lung-to-head ratio (O/E LHR) under 25\%, has higher mortality and morbidity rates and, therefore, today are offered in utero fetal surgery. Fetoscopic endoluminal tracheal occlusion $(\mathrm{FETO})^{2}$ prevents normal egress of airway fluid, which in turn induces tissue stretch, acting as a signal for lung growth. To stimulate lung maturation, it was proposed to reverse the occlusion already in utero (plug-unplug sequence), ${ }^{3}$ which also clinically seems to improve survival and morbidity. ${ }^{4,5}$ These preliminary observations are now being evaluated in a randomized controlled trial [http://www.totaltrial.eu, NIH NCT00763737 (moderate hypoplasia) and NIH NCT01240057 (severe hypoplasia)]. ${ }^{6}$

A lack of understanding of the molecular mechanisms underlying pulmonary hypoplasia in $\mathrm{CDH}$ hampers progress for potential in utero therapies and case selection. Although about $10 \%$ of $\mathrm{CDH}$ patients have chromosomal anomalies, a common genetic cause for $\mathrm{CDH}$ is unknown. ${ }^{7}$ However, it is widely accepted that the diaphragmatic defect and pulmonary hypoplasia result from a shared developmental insult. ${ }^{8,9}$ MicroRNAs (miRNAs) are small noncoding RNAs that regulate gene expression through posttranscriptional silencing of messenger RNAs. ${ }^{10}$ MicroRNAs are essential for normal organogenesis during embryonic development. For example, targeted deletion of miR-1 to 2 leads to congenital heart defects in mice. ${ }^{11}$ Previous studies have identified differential miRNA expression between various stages of lung development, but these studies did not provide much functional information. ${ }^{12}$ Whether specific miRNAs play a role in the pathogenesis of human congenital lung diseases remains unknown. Isolated $\mathrm{CDH}$ is characterized by abnormal lung development. The first objective of this study was to determine whether severe human hypoplastic $\mathrm{CDH}$ lungs display specific microRNA expression. The second objective was to determine if the obtained microRNA signature could be used as a biomarker, by evaluating its expression in tracheal and amniotic fluid samples of $\mathrm{CDH}$ patients before and after forced lung growth. The third objective was to determine how abnormal miR-200b expression influences target gene expression. This is 
the first study to identify abnormal miR-200/miR10a expression in hypoplastic $\mathrm{CDH}$ lungs and in response to forced lung growth. The expression of these microRNAs in tracheal fluid can be used to distinguish survivors of FETO from nonsurvivors. We also demonstrate that increased miR-200b expression results in decreased target gene expression via decreased TGF- $\beta$ /SMAD signaling.

\section{MATERIALS AND METHODS}

\section{MicroRNA Screen of Lung Specimens}

\section{RNA Isolation}

Erasmus MC-Sophia's institutional review board approved the study protocol, and all the experiments were performed adhering to the relevant guidelines of the Research Ethics Board of the University of Manitoba. Surrogates provided consent for the use of human tissues and biofluids. We biopsied lungs from 3 fetuses with isolated and severe $\mathrm{CDH}$ and 3 age-matched controls without lung disease (22, 22 , and 25 weeks of gestation) undergoing termination or pregnancy. Total RNA of these lung specimens was extracted using Trizol reagent (Invitrogen Life Technologies, Carlsbad, CA).

\section{MicroRNA Profiling}

The expression profile of 319 human miRNAs was investigated using a liquid-phase bead-based array according to the manufacturer's instructions. Five microgram of total RNA was biotinylated at the 3' end using the FlexmiR MicroRNA labeling kit (Luminex, Austin, TX). The labeled RNA was hybridized to locked nucleic acid (LNA) capture probes. Each probe is bound to a fluorescently dyed XMAP bead. After washes, the biotinylated miRNAs were detected by reaction with streptavidin-phycoerythrin. The samples were analyzed on a Luminex-200 instrument. The measured intensities were subtracted from a background control reaction and normalized against a set of ubiquitously expressed small nucleolar RNAs (snoRNA). Heat maps and statistical analyses were generated with the Institute for Genomic Research MultiExperiment Viewer.

\section{Real-Time Quantitative Polymerase Chain Reaction Validation of MicroRNA Profile}

We used the miRCURY LNA PCR system according to the manufacturer's instructions (Exiqon, Vedbaek, Denmark). LNA primer sets were purchased from Exiqon (Table 1). After reverse transcribing of the isolated RNAs, we used the SYBR Green assay (Bio-Rad, Hercules, CA) for real-time quantitative polymerase chain reaction (RT-qPCR) amplification. We included 3 small RNA species as endogenous controls (SNORD38B, 5S rRNA and U6 snRNA). Of these, SNORD38B had the most stable expression between different samples and was used to normalize the data.

\section{Biomarker Screen of Biofluids (Amniotic and Tracheal Fluids) \\ Clinical Evaluation}

Ultrasound evaluation was performed less than 48 hours before FETO plug (further referred to as baseline, typically around 26-28 weeks) and less than 48 hours before balloon removal (typically around 34 weeks). The degree of pulmonary hypoplasia was estimated using 2-dimentional ultrasound and was expressed as an LHR as described before. ${ }^{13,14}$ The LHR is corrected for gestational age by expressing the LHR of the index case as a proportion of what is normally expected for a gestational age-matched normal fetus (observed/expected: O/E LHR). The relative increase in $\mathrm{O} / \mathrm{E}$ LHR compared to the baseline value was expressed as follows: $[(\mathrm{O} / \mathrm{E}$ LHR unplug $-\mathrm{O} / \mathrm{E}$ baseline $) / \mathrm{O} / \mathrm{E}$ baseline $] \times 100 \%$. In addition, a functional status of the pulmonary circulation was evaluated using a maternal hyperoxygenation test. The relative difference between preand posthyperoxygenation values was expressed as deltaPI: [(baseline $\mathrm{PI}-\mathrm{PI}_{\mathrm{O} 2}$ ) / baseline $\left.\mathrm{PI}\right] \times 100 \%{ }^{15,16}$

\section{RNA Isolation}

Amniotic and tracheal fluid were collected at the time of balloon insertion and its removal $(\mathrm{n}=21)$. Amniotic fluid was retrieved at first entry into the amniotic cavity; tracheal fluid was sampled below the vocal cords, through the fetoscopic sheath, taking care not to contaminate it by irrigation fluid. The Ethics Committee of the UZ Leuven has approved the fetal treatment and prospective followup program of patients with $\mathrm{CDH}$, as well as the use of fetal fluid specimens to improve prenatal prediction of outcomes. We selected archived $\left(-80^{\circ} \mathrm{C}\right)$ sample pairs from 11 consecutive "responders" (defined as having a marked increase in O/E LHR from baseline and who were eventually surviving) and 10 "nonresponders" (ie, poor or absent increase in lung size and eventually neonatal death ${ }^{17}$ ) (Table 2).

Blinded to clinical outcome, total RNA was extracted for RTqPCR using the miRCURY RNA Isolation Kit for Biofluids (Exiqon). For normalization of sample-to-sample variation, $1 \mu \mathrm{L}$ of synthetic Caenorhabditis elegans miRNA (cel-miR-39) was added to each denatured sample. ${ }^{18,19}$ Small RNAs were then enriched and purified according to the manufacturer's protocol.

TABLE 1. LNA Primer Sets (Exiqon) Used in RT-qPCR

\begin{tabular}{|c|c|c|}
\hline LNA MicroRNA Primer Set & Target Sequence & Description \\
\hline SNORD38B & $\begin{array}{c}\text { TCTCAGTGATGAAAACTTTGTCCAGTTCTGCTACTG } \\
\text { ACAGTAAGTGAAGATAAAGTGTGTCTGAGGAGA }\end{array}$ & endogenous control \\
\hline 5S rRNA (hsa) & $\begin{array}{l}\text { GTCTACGGCCATACCACCCTGAACGCGCCCGATCTCGTCTGAT } \\
\text { CTCGGAAGCTAAGCAGGGTCGGGCCTGGTTAGTACTTG } \\
\text { GATGGGAGACCGCCTGGGAATACCGGGTGCTGTAGGCTTT }\end{array}$ & endogenous control \\
\hline U6 snRNA (hsa, mmu) & $\begin{array}{l}\text { GTGCTCGCTTCGGCAGCACATATACTAAAATTGGA } \\
\text { ACGATACAGAGAAGATTAGCATGGCCCCTGCGCAA } \\
\text { GGATGACACGCAAATTCGTGAAGCGTTCCATATTTTT }\end{array}$ & endogenous control \\
\hline hsa-miR-10a & UACCCUGUAGAUCCGAAUUUGUG & tested microRNA \\
\hline hsa-miR-27a & UUCACAGUGGCUAAGUUCCGC & tested microRNA \\
\hline hsa-miR-195 & CCAAUAUUGGCUGUGCUGCUCC & tested microRNA \\
\hline hsa-let-7a & CUAUACAAUCUACUGUCUUUC & tested microRNA \\
\hline hsa-miR-1 & UGGAAUGUAAAGAAGUAUGUAU & tested microRNA \\
\hline hsa-miR-200b & UAAUACUGCCUGGUAAUGAUGA & tested microRNA \\
\hline
\end{tabular}




\section{Real-Time Quantitative Polymerase Chain Reaction}

To optimize RT-qPCR performance, we did a dilution curve to determine what input volume affected RT-qPCR performance. On the basis of the outcome, $4 \mu \mathrm{L}$ of small RNAs from the biofluids samples were reverse transcribed using the miRCURY LNA Universal RT microRNA PCR protocol (Exiqon) in a total reaction volume of $10 \mu \mathrm{L}$. The cDNA was diluted 1:40 $\mu \mathrm{L}$ in nuclease free water to be used as a PCR template. PCR reactions for quantification of miR-200a, miR-200b, miR-200c, miR-141, miR-429, miR-10a, and cell-miR-39 were performed in triplicate and $20 \mu 1$ was used as the reaction volume. The RT-qPCR reactions were performed using an ABI 7500 Real-Time PCR System with the following cycling conditions: $95^{\circ} \mathrm{C}$ for 10 minutes, followed by 45 cycles of $95^{\circ} \mathrm{C}$ for 10 seconds and $60^{\circ} \mathrm{C}$ for 1 minute. The cycle threshold $(\mathrm{Ct})$ values were calculated with ABI $7500 \mathrm{v} 1.4 .0$ software. The target microRNAs sequences of the LNA mix primers are summarized in Table 3.

\section{Calculation of miRNA Expression}

The average expression levels of amniotic and tracheal fluid miRNAs were normalized against cel-miR-39 $9^{18,20,21}$ using the $2^{-\Delta \mathrm{Ct}}$ method. Differences between the groups are presented as $\Delta \mathrm{Ct}$, indicating the difference between the $\mathrm{Ct}$ value of the miRNA of interest and the $\mathrm{Ct}$ value of the normalizer miRNA. To ensure consistent measurements and reproducibility throughout all assays, for each PCR amplification reaction, one of the RNA samples was loaded in triplicate in all the plates, as internal control to account for any plate-to-plate variation, and the results from each plate were also normalized against an internal normalization control. The expression levels of microRNAs were normalized with the C. Elegans cel-miR-39 Spike-in kit.

\section{In Situ Hybridization and Immunohistochemistry}

We obtained postmortem neonatal lung tissues from 3 postnatal $\mathrm{CDH}$ cases and 3 age-matched controls, without lung disease (35, 37, and 40 weeks of gestation). All cases died within 1 hour after birth. In situ hybridization was carried out on $5 \mu \mathrm{m}$ sections of formalin-fixed tissue as previously described. ${ }^{22}$ Our protocol was first validated with an LNA control probe against U6 snRNA. A scramble-miR probe was used as a negative control and did not produce a signal. In situ hybridization with a probe against miR-10a

TABLE 2. Demographic Information for CDH Fetuses Undergoing FETO

\begin{tabular}{lccc}
\hline \multicolumn{4}{c}{ Baseline Characteristics of the Embryos } \\
\hline Characteristics & Responders $(\mathbf{n}=\mathbf{1 1})$ & Nonresponders $(\mathbf{n}=\mathbf{1 0})$ & \multicolumn{1}{c}{} \\
\hline O/E LHR at first evaluation (\%) & $22.5(23.6-17.5)$ & $21.6(24.0-15.9)$ & 0.87 \\
Liver herniated & $10(91 \%)$ & $9(100 \%)$ & 1.00 \\
Fetal gender (male/female) & $7(\mathrm{~m}) / 4(\mathrm{f})$ & $4(\mathrm{~m}) / 5(\mathrm{f})$ & 0.65
\end{tabular}

\begin{tabular}{lccr}
\hline FETO Data/Outcome & Responders $(\mathbf{n}=\mathbf{1 1})$ & Nonresponders $(\mathbf{n}=\mathbf{1 0})$ & $\boldsymbol{P}$ \\
\hline Gestational age at plug (wk) & $28.1(28.7-27.1)$ & $27.9(29.1-27.0)$ & 0.84 \\
Gestational Age at unplug (wk) & $34.0(34.1-33.4)$ & $34(34.5-33.9)$ & 0.36 \\
Occlusion days & $39(49-35)$ & $43(50-34)$ & 0.64 \\
Relative increase in O/E LHR & $161.7(252.4-140.8)$ & $29.8(10.4-50.2)$ & 0.0001 \\
Interval removal-delivery <24 h & $1(9 \%)$ & $0(0 \%)$ & 1.00 \\
PPROM & $5(45 \%)$ & $35.4(33 \%)$ & 0.67 \\
Gestational Age at PPROM (wk) & $35.0(35.9-32.6)$ & $38.0(38.4-36.3)$ & 1.00 \\
Gestational Age at delivery (wk) & $37.0(38.0-35.0)$ & $3195(3278-2650)$ & 0.25 \\
Birth weight (g) & $2780(3180-2160)$ & NA & 0.30 \\
Oxygen at day 28 & $6(55 \%)$ & NA & \\
NICU days & $45(61-30)$ & NA & $1(2-0)$ \\
Day of neonatal death & &
\end{tabular}

All median (IQR) or $\mathrm{n}(\%)$.

NA indicates not applicable. NICU indicates neonatal intensive care unit; PPROM, preterm premature rupture of membranes.

TABLE 3. MicroRNA Target Sequences for RT-qPCR and LNA Probes (Exiqon) Used for In Situ Hybridization

\begin{tabular}{|c|c|c|c|}
\hline Target MicroRNA & Sequence & & \\
\hline hsa-miR-200a-3p & UAACACUGUCUGGUAACGAUGU & & \\
\hline hsa-miR-200b-3p & UAAUACUGCCUGGUAAUGAUGA & & \\
\hline hsa-miR-200c-3p & UAAUACUGCCGGGUAAUGAUGGA & & \\
\hline hsa-miR-141-3p & UAACACUGUCUGGUAAAGAUGG & & \\
\hline hsa-miR-429 & UAAUACUGUCUGGUAAAACCGU & & \\
\hline hsa-miR-10a-5p & UACCCUGUAGAUCCGAAUUUGUG & & \\
\hline cel-miR-39-3p & UCACCGGGUGUAAAUCAGCUUG & & \\
\hline Probe & Sequence & Concentration & Hybridization Temperature \\
\hline hsa-miR-200b & TCATCATTACCAGGCAGTATTA & $100 \mathrm{nM}$ & $52^{\circ} \mathrm{C}$ \\
\hline hsa-miR-10a & CACAAATTCGGATCTACAGGGTA & $100 \mathrm{nM}$ & $53^{\circ} \mathrm{C}$ \\
\hline scramble-miR & GTGTAACACGTCTATACGCCCA & $100 \mathrm{nM}$ & $57^{\circ} \mathrm{C}$ \\
\hline U6, positive control & CACGAATTTGCGTGTCATCCTT & $0.1 \mathrm{nM}$ & $54^{\circ} \mathrm{C}$ \\
\hline
\end{tabular}


produced a very weak signal in postnatal lung tissues. MicroRNA species were hybridized with double-digoxigenin-labeled LNA probes (Exiqon) for 1 hour (Table 3). We detected the hybridized probes with an alkaline phosphatase-conjugated antidigoxigenin antibody (1:500) (Roche, Mannheim, Germany). Sections were immunostained with 1-step NBT/BCIP solution, containing $1 \mathrm{mM} \mathrm{lev-}$ amisole (Thermo Scientific, Rockford, IL). The slides were counterstained with methyl green (Sigma-Aldrich, St Louis, MO). We performed immunohistochemistry on neonatal lung tissue using an anti-TGF- $\beta 2$ antibody (1:100) (Abcam, Cambridge, MA) as previously described. ${ }^{23}$

\section{Microscopy and Image Analysis}

Digital microscopy was performed with the ScanScope CS system (Aperio, Vista, CA). Semiquantitative measurements of the in situ hybridization studies were obtained as follows. Images up to $200 \times$ magnification were obtained and analyzed using ImageScope software (http://www.aperio.com). The entire area of each lung section was digitally mapped using the colocalization algorithm. The blue and green stainings were first calibrated with the color deconvolution tool using positive (U6 probe without counterstain) and negative (scramble probe with methyl green counterstain) control slides, respectively. The average optical densities of each stain in the red, blue, and green channels were then entered into the colocalization algorithm. The program creates a digital map of the slide made up of 3 colors: blue for positive staining, green for nuclear counterstaining, and aqua for colocalized blue and green staining. This digital map was visually checked against the original image to ensure accuracy. The program outputs the area of each color as a percentage of all 3 colors. Positive staining was calculated by adding the percentages of blue and aqua (\% positive staining).

\section{Luciferase Assay}

We used the Cignal SMAD Reporter kit (SABiosciences, Frederick, MD) to investigate the effects of miR-200b on the TGF- $\beta$ induced signal transduction pathway. ${ }^{24}$ The construct encodes the firefly luciferase reporter gene under the control of a minimal (m)CMV promoter and tandem repeats of the SMAD transcriptional response element. The assay was carried out according to the manufacturer's instructions. Cultured human bronchial epithelial cells, BEAS-2B (ATCC, Manassas, VA), were cotransfected with $0.5 \mu \mathrm{g} / \mathrm{mL}$ of the SMAD reporter construct and $0.01 \mu \mathrm{g} / \mathrm{mL}$ of LNA-oligonucleotideinhibitor, mimic, or control (Exiqon) - using the X-tremeGENE siRNA Transfection Reagent (Roche). After 48 hours, luciferase activity was measured with a Dual-Luciferase Reporter Assay System (Promega, Madison, WI).

\section{Western Blots}

BEAS-2B cells were transfected with $0.01 \mu \mathrm{g} / \mathrm{mL}$ of LNAoligonucleotides. After 48 hours, the cells were washed and protein extracts were prepared in lysis buffer: $10 \mathrm{mM}$ Tris- $\mathrm{HCl}$ (pH 6.8), $5 \mu \mathrm{M} \beta$-glycerophosphate, $20 \mu \mathrm{M}$ EDTA, 5\% SDS, a protease inhibitor cocktail tablet, and phosphatase inhibitors $(1 \mathrm{mM}$ sodium orthovanadate, $2 \mathrm{mM}$ EDTA, $10 \mathrm{mM}$ sodium pyrophosphate, $30 \mathrm{mM}$ sodium chloride). The supernatant protein concentration was determined using RC DC Protein Assay (Bio-Rad, Hercules, CA). Fifteen micrograms of total protein was reduced with mercaptoethanol, size fractionated with SDS-PAGE and transferred to a nitrocellulose membrane (Bio-Rad). Specific proteins were detected with the following antibodies: anti-SMAD2/3 (1:750) (Cell Signaling, Danvers, MA), anti-phospho-SMAD2 (1:750) (Cell Signaling), anti-ZEB2 (1:500) (Santa Cruz Biotechnology, Santa Cruz, CA), anti-GAPDH (1:10000) (Abcam). Primary antibodies were detected using HRP-conjugated goat-anti-rabbit antibody (1:7000) (Bio-Rad) and HRP-conjugated goat-anti-mouse antibody (1:7000) (Bio-Rad). Exposed films were scanned and band densities were obtained after background subtraction using ImageJ software in a blinded fashion. Band densities were normalized against the corresponding GAPDH values.

\section{Statistical Analysis}

All quantitative data are presented as mean \pm standard error of the mean or median and interquartile range (IQR) where appropriate. Statistical analyses were performed using the statistical software SigmaStat (version 3.5; Systat Software Inc). Statistical comparisons were performed using the unpaired Student $t$ test and nonparametric Mann-Whitney $U$ test where appropriate. Paired analysis was performed using a Wilcoxon signed rank test. Differences were considered significant at $P<0.05$.

\section{RESULTS}

\section{miR-200b and miR-10a Expression Are Increased in Fetal Hypoplastic CDH Lungs}

The expression profile of the 319 human miRNAs tested is shown as a heat map in Figure E1 of the online data supplement (available at http://links.lww.com/SLA/A738). Two miRNAs, miR$200 \mathrm{~b}$ and $\mathrm{miR}-10 \mathrm{a}$, were more abundant in prenatal hypoplastic $\mathrm{CDH}$ lungs compared to age-matched normal control lungs $(P<0.01)$ (Fig. 1A). Both miR-200b and miR-10a had an approximately threefold greater expression in $\mathrm{CDH}$ lungs compared to age-matched control lungs (Fig. 1B). Four other miRNAs - miR-27a, miR-195, let-7a, and miR-1 - were tested on the basis of near significant differences in the microarray analysis (Fig. E1, available at http://links.lww.com/ SLA/A738). None of these had a statistically significant difference in expression in $\mathrm{CDH}$ lungs compared to control lungs using RT-qPCR (results not shown).

\section{Tracheal Fluid: Responders Have Higher Expression of miR-200 Than Nonresponders After FETO}

On the basis of these observations, we focused on validating and further exploring the expression of the miR-200 family (miR200a, miR-200b, miR-200c, miR-141, and miR-429) and miR-10a in tracheal and amniotic fluid samples of $\mathrm{CDH}$ patients at baseline (plug) as well as following forced lung growth by FETO (unplug). Responders (ie, with measurable lung growth and eventually surviving) to FETO had increased expression of the miR-200 family in their tracheal fluid. Expression of miR-200 was higher after FETO (unplug) in responders compared to nonresponders (Figs. 2A-E). However, their baseline expression was not different. Conversely, tracheal fluid miR-10a expression was lower in responders than in nonresponders at baseline (plug). After FETO (unplug), the expression of miR-10a increased in responders but remained unchanged in nonresponders (Fig. 2F).

\section{Expression of miR-200 Family and miR-10a in Amniotic Fluid Decreases After FETO}

After FETO (unplug), the amniotic fluid levels of the investigated miRNAs did not mirror what was observed in the tracheal fluid. The amniotic fluid levels were overall lower. Because the lungs contribute largely to the amniotic content in the third trimester and were occluded during FETO, this was anticipated. ${ }^{25}$ The expression profiles of all investigated microRNAs exhibited a similar trend: FETO responders had significantly higher expression than nonresponders (Fig. 3). More specifically, expression of miR-200a and miR-200c significantly decreased after FETO (unplug) (Figs. 3A and C). Expression of miR-200a, miR-200c, miR-141, and miR-10a was higher in amniotic fluid of survivors than in nonsurvivors after FETO (unplug) (Figs. 3A, C, D, and F). 


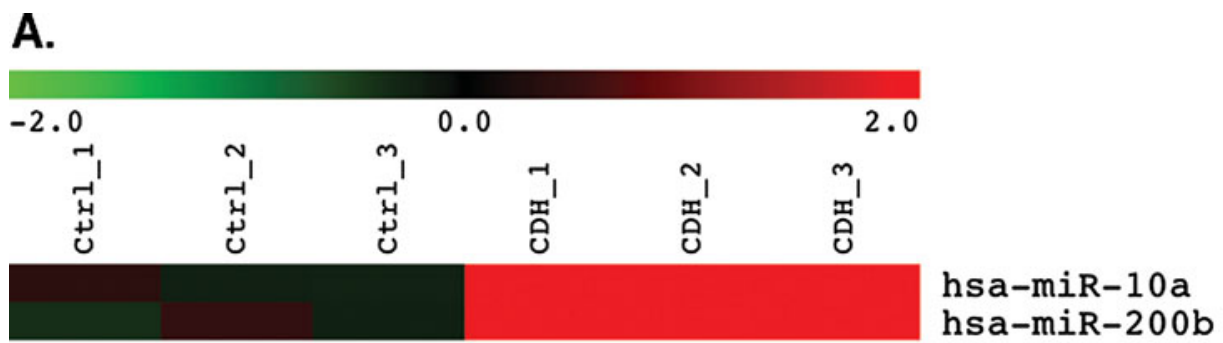

B.
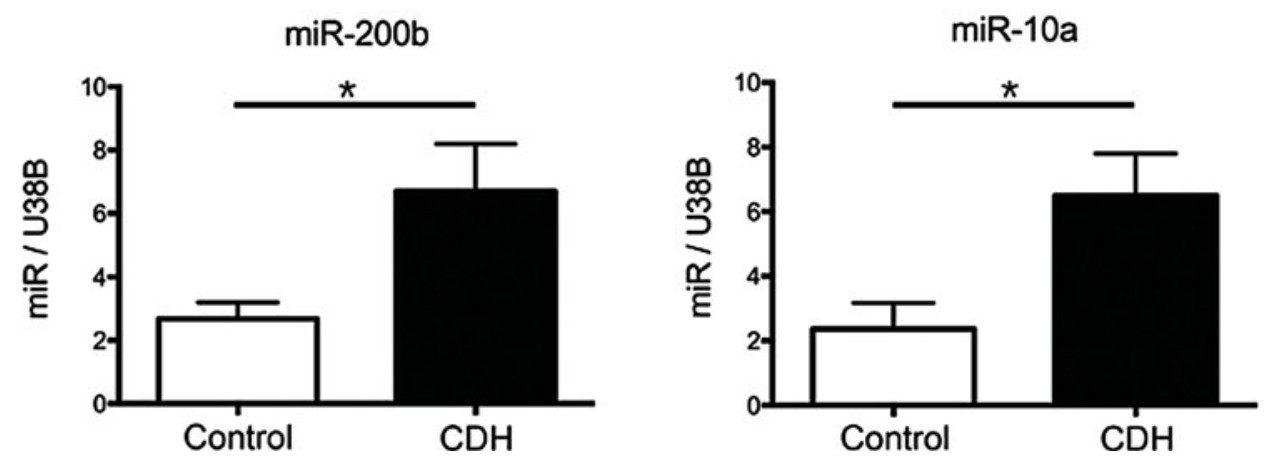

FIGURE 1. Upregulation of miR-200b and miR-10a in prenatal lungs in CDH. Total RNA was extracted from $3 \mathrm{CDH}$ cases and 3 age-matched controls (Ctrl). A, Heat map representation of normalized microarray data (log 2 scale). Of the 319 miRNAs tested, miR-200b and miR-10a were overexpressed in hypoplastic lungs $(P<0.01)$. B, Real-time PCR confirmed overexpression of miR-200b and miR-10a in CDH ( $\left.{ }^{*} P<0.05\right)$. miRNA expression is normalized relative to SNORD38B (U38B).

\section{A Good Pulmonary Response After FETO Also Alters Pulmonary Vascular Reactivity to Oxygen}

The median relative increase in O/E LHR in fetuses surviving after birth was significantly higher than in nonresponders [161.7 (IQR: 252.4-140.8) vs 29.8 (IQR: 10.4-50.2); $P<0.0001]$ (Table 2). Vascular reactivity could be assessed in 4 of 10 poor responders and 6 of 11 good responders. In fetuses with poor response after FETO, we did not observe a change in median deltaPI $[-2.0 \%$ (IQR: -10.3 to 31.0 ) vs $13.6 \%$ (IQR: $1.3-28.2$ ); $P=0.63$ ]. In contrast in fetuses with a good response, median deltaPI increased significantly after FETO [4.6\% (IQR: -1.3 to 11.9 ) vs $23.0 \%$ (IQR: $3.4-39.8$ ); $P=0.03$ ].

\section{Expression of miR-200b Is Higher in the Distal Part of Postnatal Hypoplastic Lungs}

We performed in situ hybridization to determine miR-200b expression in a separate set of postnatal lung sections. Hypoplastic CDH lungs were characterized by increased miR-200b expression, particularly in the terminal saccules and alveoli (Fig. 4A). We used image analysis software to generate color-coded maps and quantify the area of positive staining for each lung section. Using this method, neonatal hypoplastic CDH lungs displayed increased miR-200b expression compared to age-matched control lungs (Fig. 4B).

In situ hybridization for miR-200b produced a highly specific staining pattern in normal neonatal lungs. Bronchial epithelial cells were intensely positive for miR-200b (Fig. 4C, thick black arrow). In contrast, parabronchial smooth muscle cells were predominantly negative for miR-200b (Fig. 4C, thick white arrow). Terminal saccules contained a mixed population of positive (alveolar type II cells) and negative-staining cells. In blood vessels, endothelial cells (inner layer) were positive for miR-200b (Fig. 4C, black arrowhead). Perivascular smooth muscle cells, on the other hand, were negative (Fig. 4C, white arrowhead). Mesothelial cells of the pleura were positive for miR-200b (results not shown).

\section{TGF- $\beta 2$, a miR-200b Target Gene, Expression Is Decreased in Hypoplastic CDH Lungs}

Others have identified components of the TGF- $\beta$-induced signal transduction pathway as the major targets of the miR-200 family. ${ }^{26}$ We used immunohistochemistry to assess TGF- $\beta 2$ expression in postnatal lung tissues. The cellular distribution of TGF- $\beta 2$ was very similar to miR-200b, that is, expressed in bronchial epithelial cells and vascular endothelial cells, but absent from parabronchial and perivascular smooth muscle cells. CDH lungs displayed decreased TGF- $\beta 2$ expression in terminal saccules compared to age-matched control lungs (Fig. 5A).

\section{miR-200b Downregulates TGF- $\beta$ Signaling in Human Bronchial Epithelial Cells}

Downstream effects of TGF- $\beta$-induced signal transduction are initiated through SMAD2/3 phosphorylation and its subsequent nuclear translocation. ${ }^{27}$ We used a luciferase bioluminescent assay to measure SMAD-induced gene expression and the impact of changing miR-200b expression in cultures of human bronchial epithelial cells. In a pilot experiment measuring miR-200b expression in different cell lines relevant to lung, we demonstrated that these cells exhibit abundant miR-200b expression (results not shown). In absence of exogenous TGF- $\beta$, bronchial epithelial cells displayed very little SMAD-dependent luciferase activity. This low baseline activity did not change when miR-200b mimics were added to the culture medium. On the contrary, inhibitors of miR-200b increased SMAD-luciferase activity by several orders of magnitude (Fig. 5B). Collectively, these data suggest that basal TGF- $\beta$-induced signaling 


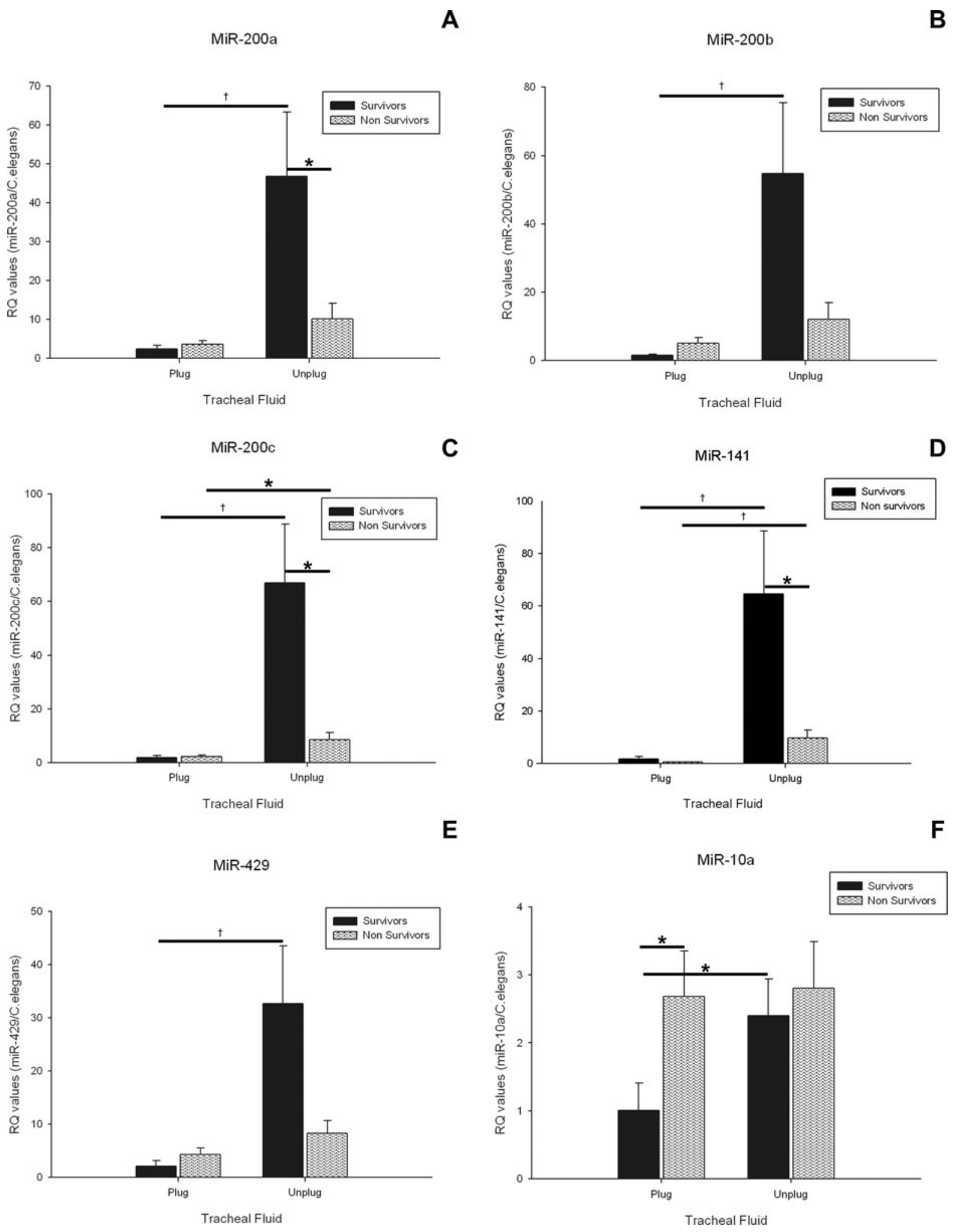

FIGURE 2. miR-200 family members and miR-10a expression analysis in tracheal fluid samples of surviving and nonsurviving patients with CDH undergoing FETO. Expression levels of miR-200a (A), miR-200b (B), miR-200c (C), miR-141 (D), miR-429 (E), and miR-10a (F) in tracheal fluid samples. Expression levels of these microRNAs were normalized to cel-miR-39. Statistical analysis was performed using the Mann-Whitney $U$ test for independent comparisons between surviving and non-surviving patients and a Wilcoxon signed-rank test for paired comparisons between plug and unplug, ${ }^{*} P<0.05 ; \dagger P<0.01 ; \ddagger P<0.001$. 
A

B
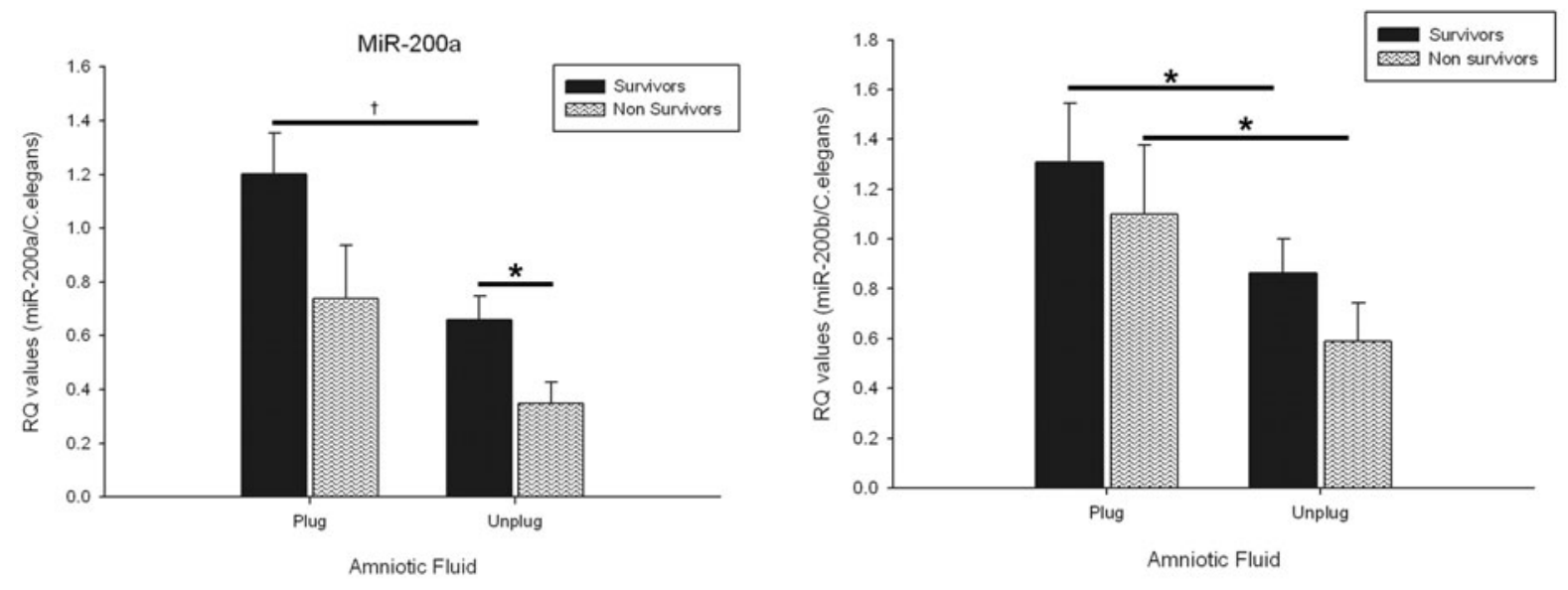

C
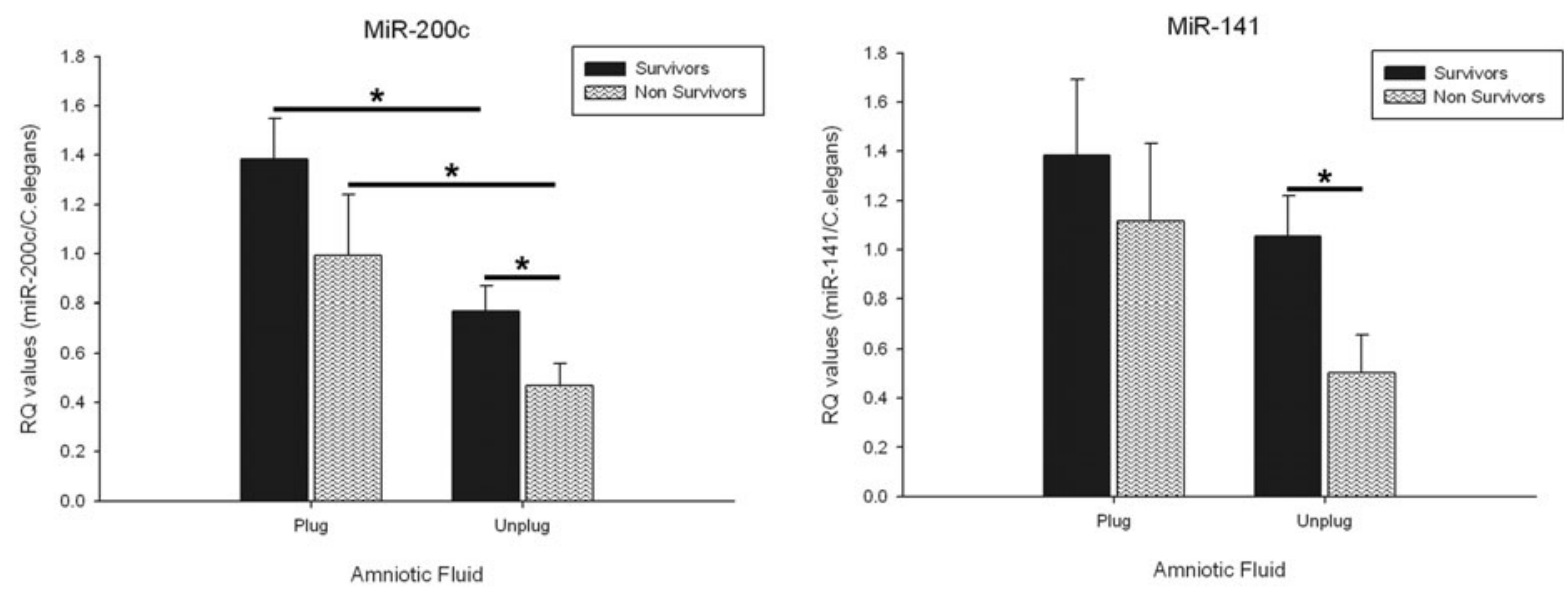

E
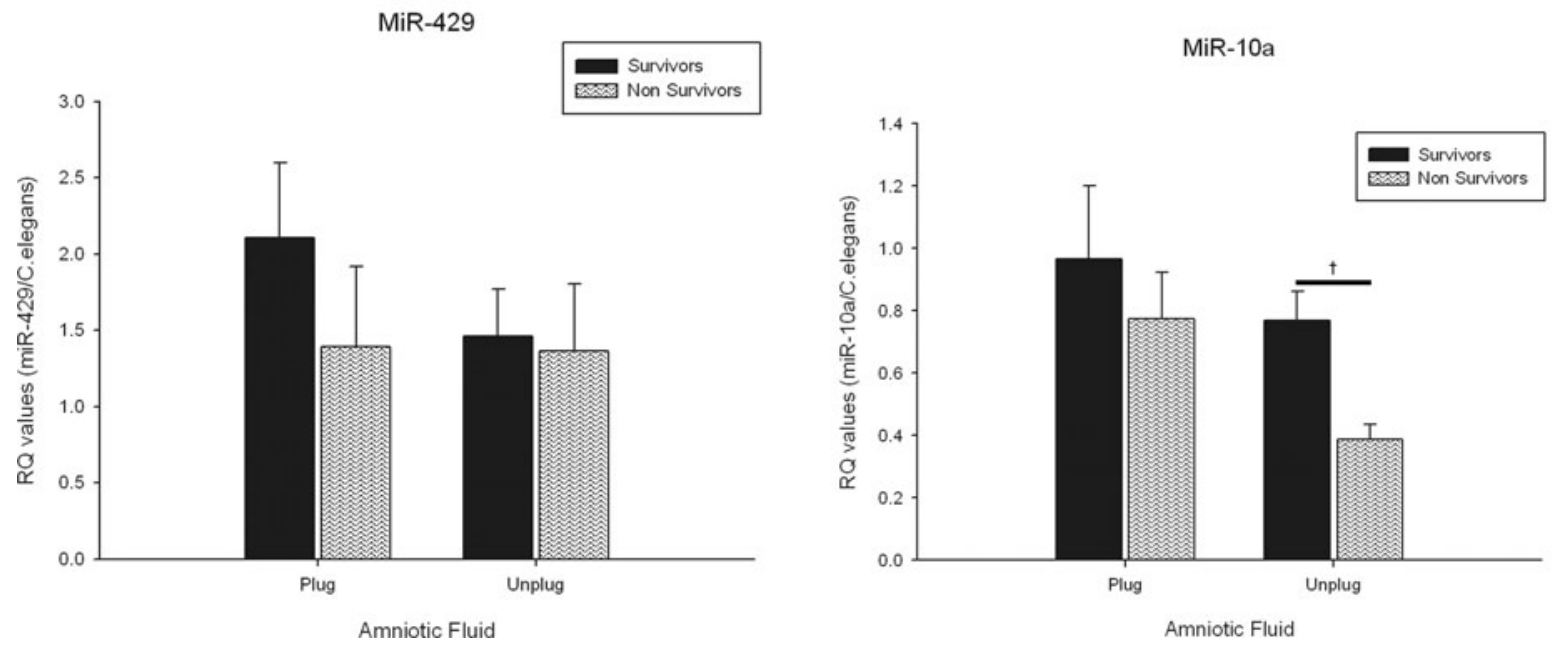

FIGURE 3. miR-200 family members and miR-10a expression analysis in amniotic fluid samples of surviving and nonsurviving patients with CDH undergoing FETO. Amniotic fluid levels of miR-200a (A), miR-200b (B), miR-200c (C), miR-141 (D), miR-429 (E), and miR-10a (F). Expression levels of these microRNAs were normalized to cel-miR-39. Statistical analysis was performed using the Mann-Whitney $U$ test, for independent comparisons between surviving and non-surviving patients and a Wilcoxon signed-rank test for paired comparisons between plug and unplug, ${ }^{*} P<0.05 ; \dagger P<0.01$. 


\section{A}
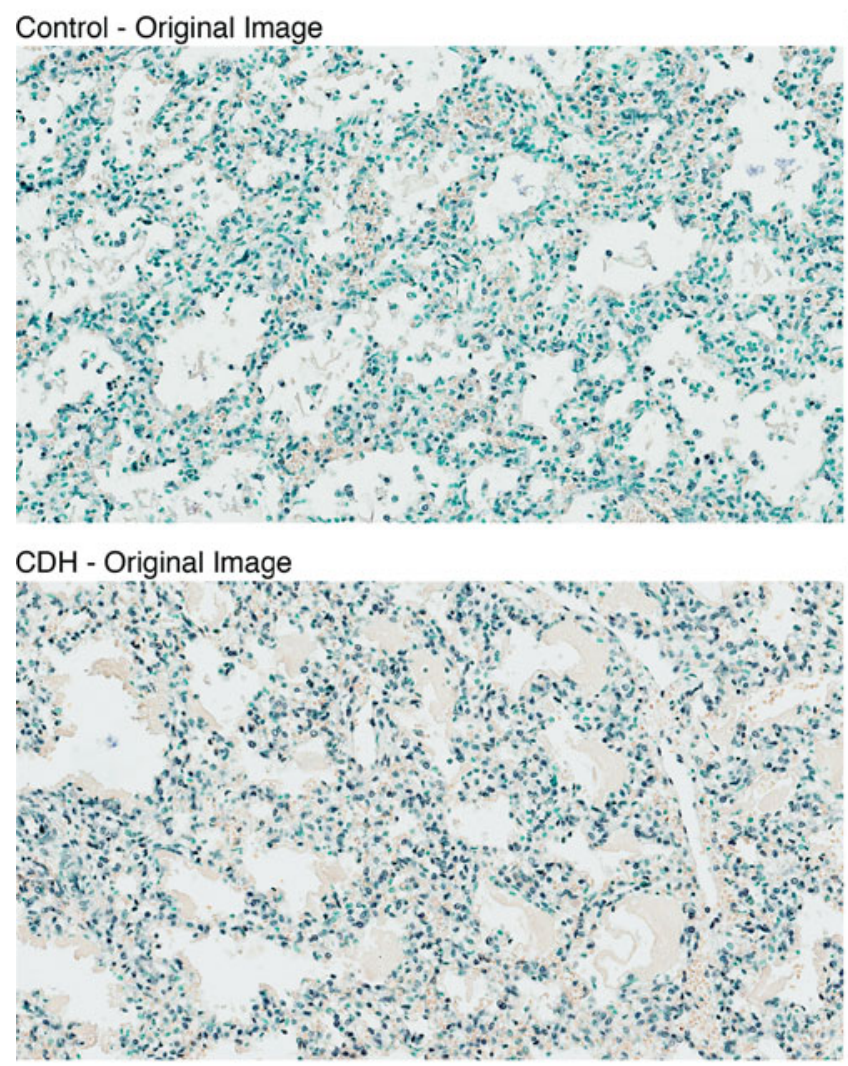

\section{Control - Color-coded Map}

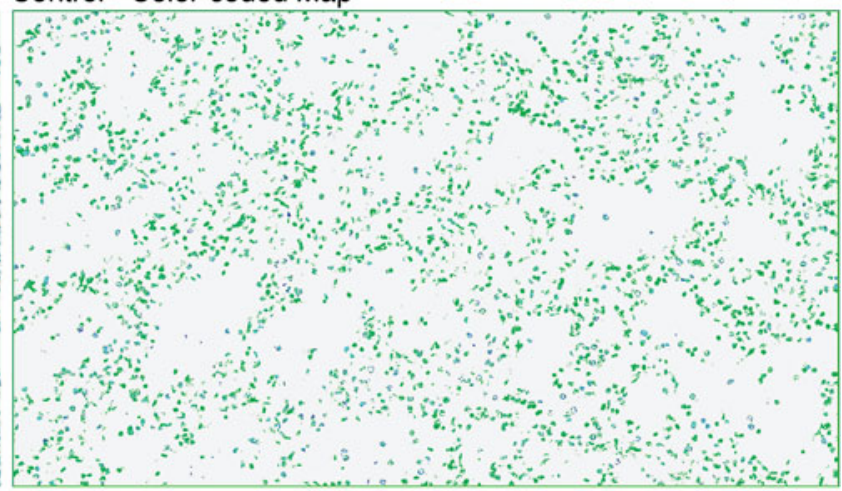

$\mathrm{CDH}$ - Color-coded Map

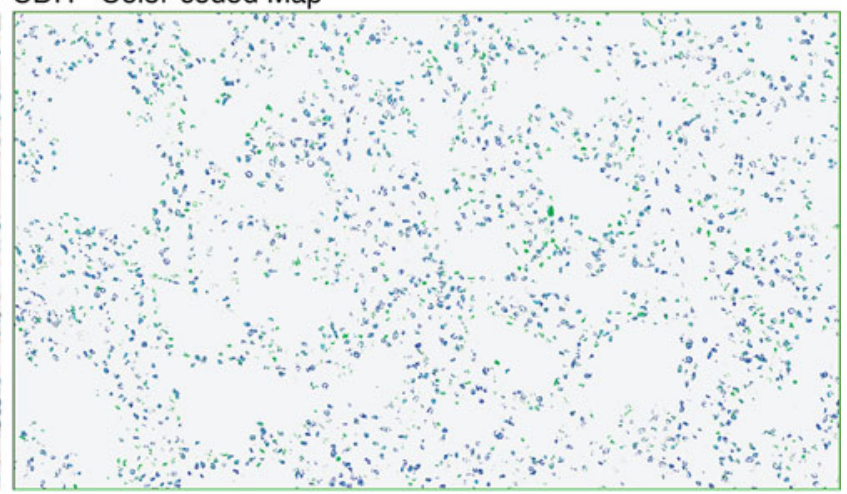

B

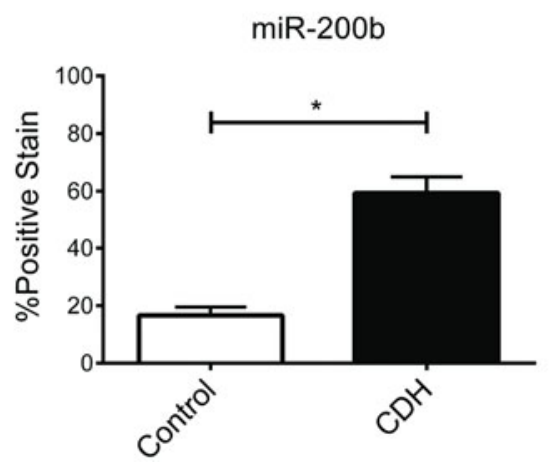

C

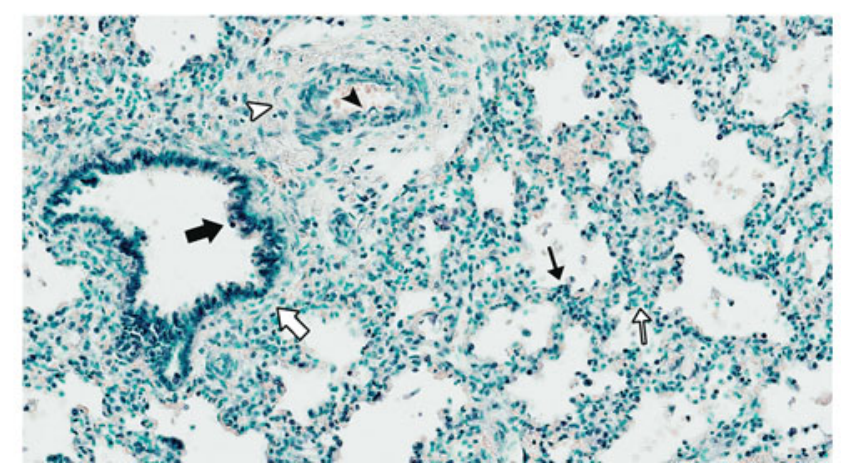

FIGURE 4. In situ hybridization for miR-200b (blue stain) in postnatal lung (methyl green counterstain, $200 \times$ magnification). A, Terminal saccules of control vs $\mathrm{CDH}$ lungs (color-coded maps: blue $=$ positive staining, green = negative staining, aqua $=$ colocalized positive and negative staining). B, Area of positive staining (\% blue $+\%$ aqua) was calculated for each lung section $\left({ }^{*} P<0.05\right)$. C, miR-200b expression in normal postnatal lung. In bronchioles, miR-200b is expressed in epithelial cells (black thick arrow), but is absent from parabronchial smooth muscle cells (white thick arrow). In blood vessels, miR-200b is expressed in endothelial cells (black arrowhead) but is absent from the surrounding smooth muscle cells (white arrowhead). Terminal saccules contain a mixed population of miR-200b-positive (black thin arrow) and miR-200b-negative (white thin arrow) cells.

is tempered by steady state levels of miR-200b, and that reducing miR-200b is permissive for TGF- $\beta$-induced signaling.

To clarify mechanisms that might underpin altered basal SMAD-mediated responses, we next performed Western blotting using antibodies against total SMAD2/3 and phospho-SMAD2/3 (p-SMAD). Addition of miR-200b inhibitors or mimics to cultures of bronchial epithelial cells resulted in a nearly twofold increase or decrease, respectively, in p-SMAD levels; however, total SMAD2/3 abundance was unaffected (Fig. 5C). ZEB2 is a downstream transcriptional repressor in the TGF- $\beta$ /SMAD signal transduction pathway and a putative target of miR-200b based on sequence complementarity. ${ }^{27}$ Addition of miR-200b inhibitors or mimics to cultures of bronchial epithelial cells resulted in a nearly twofold increase or decrease, respectively, in ZEB2 levels (Fig. 5C). 
A.

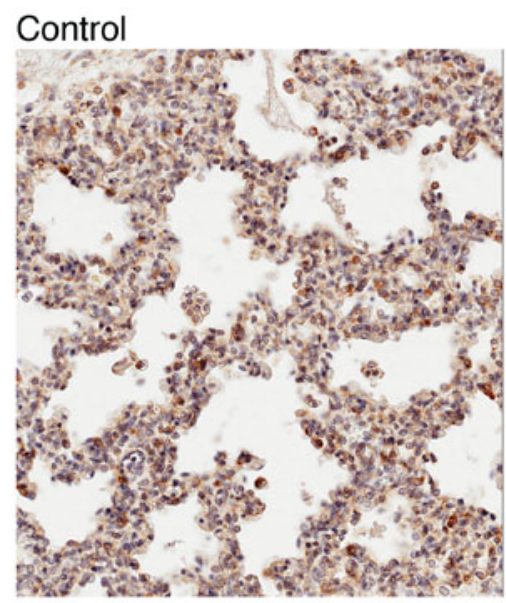

B.

\section{$\mathrm{CDH}$}

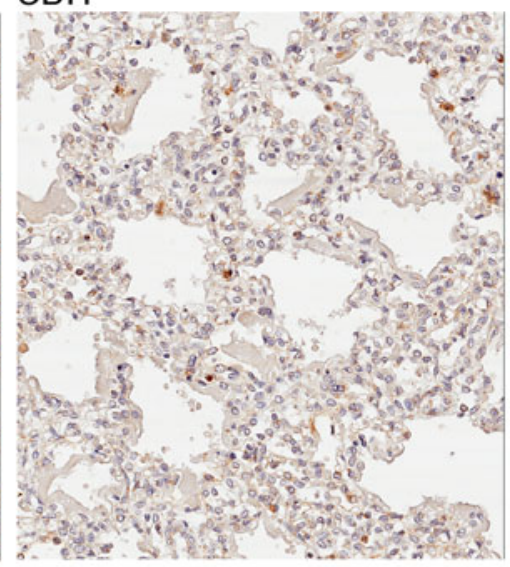

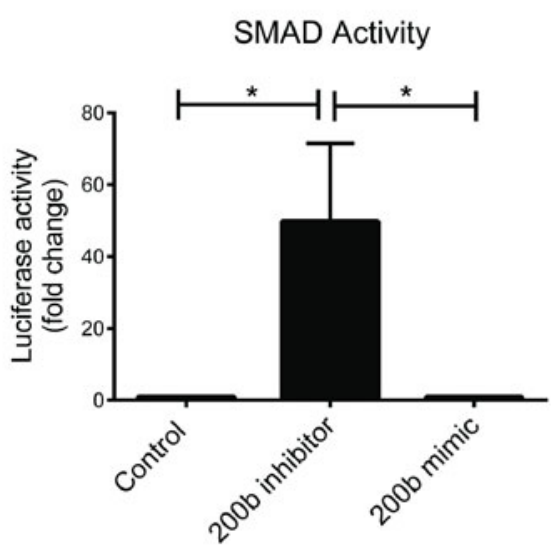

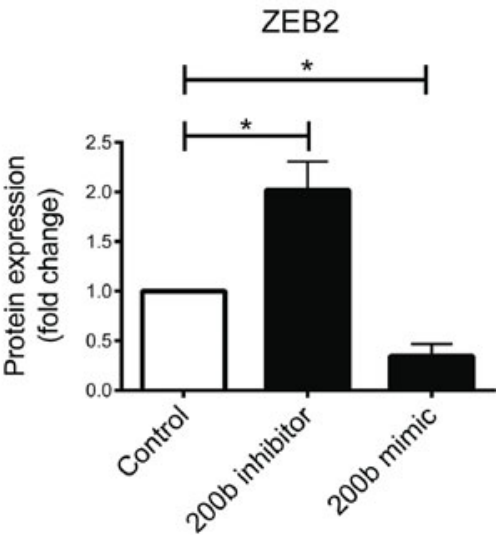

FIGURE 5. miR-200b Target Gene Expression. A, Immunohistochemistry for TGF- $\beta 2$ (brown stain) in control vs CDH postnatal lungs (hematoxylin counterstain, $200 \times$ magnification). B, SMAD-luciferase reporter assay in cultures of bronchial epithelial cells. Luciferase activity was measured after a 48-hour incubation with miR-200b inhibitor, mimic, or control oligonucleotide. C, Immunoblotting for ZEB2 and phospho-SMAD (p-SMAD). Bronchial epithelial cells were incubated for 48 hours with miR-200b inhibitor, mimic, or control oligonucleotide $\left({ }^{*} P<0.05\right)$.

\section{DISCUSSION}

The lack of success in identifying a pure genetic cause for $\mathrm{CDH}$ prompted us to investigate the role of epigenetics and more in particular microRNAs. Our study is the first to demonstrate altered miRNA expression in human congenital lung disease. Homogenates of hypoplastic lungs from $\mathrm{CDH}$ fetuses display miR-200b and miR-10a overexpression. We then selected tracheal and amniotic fluid samples from fetuses with appropriate or insufficient lung growth after fetal surgery. Responders could be discriminated from nonresponders by a significantly higher miR-200 expression in their tracheal fluid, suggesting that stimulated lung development is associated with an increase in miR-200 expression. Upregulation of miR-200b persists in terminal saccules of $\mathrm{CDH}$ patients and is associated with decreased TGF- $\beta 2$ expression. In vitro, miR-200b inhibits TGF- $\beta /$ SMAD signaling in bronchial epithelial cells.

Using in situ hybridization, we determined that miR-200b is overexpressed in the terminal saccules of postnatal CDH lungs compared to age-matched controls. miR-200b is a member of the miR-200 family, including also miR-200a, miR-200c, miR-141, and miR-429. ${ }^{26,28-32}$ These miRNAs have similar sequences and are transcribed in 2 clusters: miR-200b, miR-200a, and miR-429 share a common transcription start site on chromosome 1 , whereas miR-200c and miR-141 are transcribed as a single unit from chromosome 12. There is increasing evidence that members of the miR-200 family play a role in cancer. Several studies have demonstrated that miR-200 expression is upregulated in epithelial tissues, where they contribute to the epithelial cell phenotype by inhibiting mesenchymal gene expression. ${ }^{29}$ We observed strong miR-200b expression in bronchial and alveolar epithelial cells. In contrast, parabronchial smooth muscle cells, which are differentiated mesenchymal cells, were negative for miR-200b. Mesothelial and endothelial cells were also positive for miR-200b. We have previously demonstrated that hypoplastic $\mathrm{CDH}$ lungs are characterized by a disturbed epithelial/fibroblast cell ratio in favor of fibroblasts. ${ }^{23}$

The miR-200 family functions by inhibiting several genes involved in the TGF- $\beta$ /SMAD signaling pathway. ${ }^{26,33}$ Increased TGF- $\beta$ activity enhances miR-200 expression as part of a negative feedback loop. ${ }^{34}$ Others have previously demonstrated in the surgical 
sheep model of CDH that FETO increased TGF- $\beta 2$ expression in hypoplastic lungs. ${ }^{35}$ In addition, increased TGF- $\beta$ expression has been observed in hypoplastic lungs in the nitrofen-induced rat model of $\mathrm{CDH}^{36-38}$ Here, we observed increased miR-200 expression in prenatal and postnatal lung tissues in $\mathrm{CDH}$ and tracheal fluid samples of $\mathrm{CDH}$ patients responding to FETO. Our data suggest that the increase in miR-200 might result from an inherent increased TGF- $\beta$ expression in hypoplastic lungs. In addition, FETO can increase miR-200b expression even further in lungs responding to mechanical stretch via upregulation of TGF- $\beta$ expression in these lungs. The primary insult leading to $\mathrm{CDH}$ and pulmonary hypoplasia occurs very early in gestation when a diagnosis cannot be made yet. ${ }^{39,40}$ Because of the unavailability of human fetal tissues during these early stages of lung development, we were unable to investigate miRNA or TGF- $\beta$ expression at the time of the primary insult. In postnatal lung tissues of CDH cases, we observed decreased TGF- $\beta 2$ expression, particularly in the terminal saccules. During fetal lung development, endogenous TGF- $\beta$ blocks hormone-induced type II epithelial cell differentiation. ${ }^{41}$ Decreased TGF- $\beta$ activity in late stages of lung development might explain why human cases of $\mathrm{CDH}$ display normal surfactant maturation. ${ }^{42,43}$ In addition, exogenous surfactant has been demonstrated to be of no benefit in the treatment of pulmonary hypoplasia associated with $\mathrm{CDH} .^{44,45}$

We established the inhibitory effect of miR-200b on TGF- $\beta$ / SMAD signaling in human bronchial epithelial cells. Given their epithelial phenotype, these cells displayed a very low level of intrinsic SMAD2/3 activity. miR-200b inhibition significantly enhanced SMAD2/3 phosphorylation, suggesting that in bronchial epithelial cells, miR-200b functions by suppressing endogenous TGF- $\beta$ activity. Both increased and decreased TGF- $\beta$ signaling can lead to abnormal lung development. ${ }^{46-48}$ Our results suggest that miR-200b plays an important role in normal lung development by closely regulating TGF- $\beta$ signaling.

Extracellular microRNAs have recently emerged as potential biomarkers because they have been shown to be associated with various pathological conditions including cancer. Biomarkers have also successfully been used to stratify therapy and/or to evaluate response to therapy. Both miR-200 and miR-10a have earlier served as biomarkers in some conditions. Most of these studies have focused on their role in cancer progression. Increased serum miR-200c expression is associated with colorectal cancer progression and metastasis ${ }^{49}$ and gastric cancer. ${ }^{50}$ In contrast, decreased miR-200a expression is associated with poor prognosis and recurrence in ovarian cancer. ${ }^{51}$ The role of miR-10a as a biomarker is less well established. A recent study showed overexpression of miR-10a in human pancreatic cancer cells. ${ }^{52}$ Furthermore, a combination of miR-10a and miR-200b has recently been reported to be a valuable microRNA signature for metastatic medullary thyroid carcinoma ${ }^{53}$ and bladder cancer. ${ }^{54} \mathrm{We}$ have shown that tracheal fluid expression of miR-200 and miR-10a can serve as a marker of response to FETO. Although FETO decreased amniotic miRNA expression, survivors could be distinguished by higher expression of miR-200a, miR-200c, miR-141, and miR-10a.

Considering our study limitations, we are aware that this study has a relatively small sample size, no detailed phenotypic information on the termination of pregnancy patients, a narrow window of gestational age in the FETO group and most importantly, no control amniotic or tracheal fluids. For obvious reasons, it would be unethical to try and obtain tracheal fluid samples from control patients. The first experiment was carefully planned to include only prenatal lungs for identification of potential microRNAs as etiological factors of pulmonary hypoplasia in $\mathrm{CDH}$. $\mathrm{CDH}$ is typically diagnosed at second trimester ultrasound ${ }^{55}$ and therefore, our 3 pairs of prenatal $\mathrm{CDH}$ and control lungs (22-25 weeks of gestation) form a unique homogenous set of severely hypoplastic lungs, which were not exposed to confounding pre- or postnatal factors directly interfering with lung development (steroids, ventilation, etc). These lungs were obtained from terminations of pregnancies for medical reasons and processed for research purposes within 1 hour of termination. In addition, the tracheal and amniotic fluid samples were carefully collected as part of a systematic collection of biofluids in a very well characterized homogenous group of patients undergoing FETO.

\section{CONCLUSIONS}

We are the first to report altered microRNA expression in clinical cases with abnormal lung development due to severe isolated $\mathrm{CDH}$. Future studies should reveal if manipulating miR-200 and miR-10a expression improves the natural course in $\mathrm{CDH}$ patients and their abnormal lung development.

\section{ACKNOWLEDGMENTS}

P.P.-T. and J.D. contributed equally to this article.

The authors thank Dr Andrew Halayko and Dr Vinaya Siragam for their valuable suggestions to improve the manuscript. The author contributions were as follows: Patricia Pereira-Terra, Ramin Kholdebarin, Anne A. Boerema-de Munck, Jinxia Wang, Philip DeKoninck, Nagmeh Khoshgoo, Fuqin Zhu, Barbara M. Iwasiow, and Richard Keijzer acquired and analyzed the data. Jan A. Deprest and Philip DeKoninck acquired the tracheal and amniotic fluid samples. Dick Tibboel and Robbert J. Rottier acquired the lung samples. Jan Deprest, Martin Post, Dick Tibboel, and Richard Keijzer delineated the hypothesis and designed the study. Patricia Pereira-Tera, Jan Deprest, Ramin Kholdebarin, Robbert J. Rottier, Martin Post, Jorge Correia-Pinto, Dick Tibboel, and Richard Keijzer wrote and revised the manuscript.

\section{REFERENCES}

1. Langham MR, Kays DW, Ledbetter DJ, et al. Congenital diaphragmatic hernia Epidemiology and outcome. Clin Perinatol. 1996;23:671-688.

2. Jani JC, Nicolaides KH, Gratacós E, et al. Severe diaphragmatic hernia treated by fetal endoscopic tracheal occlusion. Ultrasound Obstet Gynecol. 2009;34:304-310

3. Flageole H, Evrard VA, Piedboeuf B, et al. The plug-unplug sequence: an important step to achieve type II pneumocyte maturation in the fetal lamb model. J Pediatr Surg. 1998;33:299-303.

4. Doné E, Gratacos E, Nicolaides KH, et al. Predictors of neonatal morbidity in fetuses with severe isolated congenital diaphragmatic hernia undergoing fetoscopic tracheal occlusion. Ultrasound Obstet Gynecol. 2013;42:77-83.

5. Deprest J, Nicolaides K, Done' E, et al. Technical aspects of fetal endoscopic tracheal occlusion for congenital diaphragmatic hernia. J Pediatr Surg. 2011;46:22-32.

6. Dekoninck P, Gratacos E, Van Mieghem T, et al. Results of fetal endoscopic tracheal occlusion for congenital diaphragmatic hernia and the set up of the randomized controlled TOTAL trial. Early Hum Dev. 2011;87:619-624.

7. Veenma DCM, de Klein A, Tibboel D. Developmental and genetic aspects of congenital diaphragmatic hernia. Pediatr Pulmonol. 2012;47:534-545.

8. Keijzer R, Liu J, Deimling J, et al. Dual-hit hypothesis explains pulmonary hypoplasia in the nitrofen model of congenital diaphragmatic hernia. Am J Pathol. 2000;156:1299-1306.

9. Allan DW, Greer JJ. Pathogenesis of nitrofen-induced congenital diaphragmatic hernia in fetal rats. $J$ Appl Physiol. 1997;83:338-347.

10. Ambros V. The functions of animal microRNAs. Nature. 2004;431:350-355.

11. Zhao Y, Ransom JF, Li A, et al. Dysregulation of cardiogenesis, cardiac conduction, and cell cycle in mice lacking miRNA-1-2. Cell. 2007;129:303-317.

12. Mujahid S, Logvinenko T, Volpe MV, et al. miRNA regulated pathways in late stage murine lung development. BMC Dev Biol. 2013;13:13.

13. Metkus AP, Filly RA, Stringer MD, et al. Sonographic predictors of survival in fetal diaphragmatic hernia. J Pediatr Surg. 1996;31:148-151; discussion $151-152$

14. Jani J, Nicolaides KH, Keller RL, et al. Observed to expected lung area to head circumference ratio in the prediction of survival in fetuses with isolated diaphragmatic hernia. Ultrasound Obstet Gynecol. 2007;30:67-71. 
15. Done E, Allegaert K, Lewi $\mathrm{P}$, et al. Maternal hyperoxygenation test in fetuses undergoing FETO for severe isolated congenital diaphragmatic hernia. Ultrasound Obstet Gynecol. 2011;37:264-271.

16. DeKoninck P, Lewi P, Done E, et al. Sonographic evaluation of vascular pulmonary reactivity following oxygen administration in fetuses with normal lung development. Prenat Diagn. 2012;32:1300-1304.

17. Cannie MM, Jani JC, De Keyzer F, et al. Evidence and patterns in lung response after fetal tracheal occlusion: clinical controlled study. Radiology. 2009;252:526-533.

18. Argyropoulos $\mathrm{C}$, Wang $\mathrm{K}$, McClarty $\mathrm{S}$, et al. Urinary microRNA profiling in the nephropathy of type 1 diabetes. PLoS One. 2013;8:e54662.

19. Mitchell PS, Parkin RK, Kroh EM, et al. Circulating microRNAs as stable blood-based markers for cancer detection. Proc Natl Acad Sci USA. 2008;105:10513-10518.

20. Kroh EM, Parkin RK, Mitchell PS, et al. Analysis of circulating microRNA biomarkers in plasma and serum using quantitative reverse transcription-PCR (qRT-PCR). Methods. 2010;50:298-301.

21. Weber JA, Baxter DH, Zhang S, et al. The microRNA spectrum in 12 body fluids. Clin Chem. 2010;56:1733-1741.

22. Jørgensen S, Baker A, Møller S, et al. Robust one-day in situ hybridization protocol for detection of microRNAs in paraffin samples using LNA probes. Methods. 2010;52:375-381.

23. Van Loenhout RB, Tseu I, Fox EK, et al. The pulmonary mesenchymal tissue layer is defective in an in vitro recombinant model of nitrofen-induced lung hypoplasia. Am J Pathol. 2012;180:48-60.

24. Leeper NJ, Raiesdana A, Kojima Y, et al. MicroRNA-26a is a novel regulator of vascular smooth muscle cell function. J Cell Physiol. 2011;226:1035-1043.

25. Evrard VA, Flageole H, Deprest JA, et al. Intrauterine tracheal obstruction, a new treatment for congenital diaphragmatic hernia, decreases amniotic fluid sodium and chloride concentrations in the fetal lamb. Ann Surg. 1997;226:753758 .

26. Burk U, Schubert J, Wellner U, et al. A reciprocal repression between ZEB1 and members of the miR-200 family promotes EMT and invasion in cancer cells. EMBO Rep. 2008;9:582-589.

27. Xu J, Lamouille S, Derynck R. TGF-beta-induced epithelial to mesenchymal transition. Cell Res. 2009;19:156-172.

28. Christoffersen NR, Silahtaroglu A, Orom UA, et al. miR-200b mediates posttranscriptional repression of ZFHX1B. RNA. 2007;13:1172-1178.

29. Gregory PA, Bert AG, Paterson EL, et al. The miR-200 family and miR-205 regulate epithelial to mesenchymal transition by targeting ZEB1 and SIP1. Nat Cell Biol. 2008;10:593-601.

30. Hurteau GJ, Carlson JA, Spivack SD, et al. Overexpression of the microRNA hsa-miR-200c leads to reduced expression of transcription factor 8 and increased expression of E-cadherin. Cancer Res. 2007;67:7972-7976.

31. Korpal M, Lee ES, Hu G, et al. The miR-200 family inhibits epithelialmesenchymal transition and cancer cell migration by direct targeting of E-cadherin transcriptional repressors ZEB1 and ZEB2. $J$ Biol Chem. 2008;283:14910-14914.

32. Park S-M, Gaur AB, Lengyel E, et al. The miR-200 family determines the epithelial phenotype of cancer cells by targeting the E-cadherin repressors ZEB1 and ZEB2. Genes Dev. 2008;22:894-907.

33. Gregory PA, Bracken CP, Smith E, et al. An autocrine TGF-beta/ZEB/ miR-200 signaling network regulates establishment and maintenance of epithelial-mesenchymal transition. Mol Biol Cell. 2011;22:1686-1698.

34. Kato M, Arce L, Wang M, et al. A microRNA circuit mediates transforming growth factor- $\beta 1$ autoregulation in renal glomerular mesangial cells. Kidney Int. 2011;80:358-368.

35. Quinn TM, Sylvester KG, Kitano Y, et al. TGF-beta2 is increased after fetal tracheal occlusion. J Pediatr Surg. 1999;34:701-704; discussion 704-705.
36. Oue T, Shima H, Taira Y, et al. Administration of antenatal glucocorticoids upregulates peptide growth factor gene expression in nitrofen-induced congenital diaphragmatic hernia in rats. J Pediatr Surg. 2000;35:109-112.

37. Yamataka T, Puri P. Active collagen synthesis by pulmonary arteries in pulmonary hypertension complicated by congenital diaphragmatic hernia. J Pediatr Surg. 1997;32:682-687.

38. Teramoto H, Shinkai M, Puri P. Altered expression of angiotensin II receptor subtypes and transforming growth factor-beta in the heart of nitrofen-induced diaphragmatic hernia in rats. Pediatr Surg Int. 2005;21:148-152.

39. Greer JJ, Cote D, Allan DW, et al. Structure of the primordial diaphragm and defects associated with nitrofen-induced CDH. J Appl Physiol. 2000;89:21232129.

40. Babiuk RP, Zhang W, Clugston R, et al. Embryological origins and development of the rat diaphragm. J Comp Neurol. 2003;455:477-487.

41. McDevitt TM, Gonzales LW, Savani RC, et al. Role of endogenous TGF-beta in glucocorticoid-induced lung type II cell differentiation. Am J Physiol Lung Cell Mol Physiol. 2007;292:L249-L257.

42. Janssen DJMT, Tibboel D, Carnielli VP, et al. Surfactant phosphatidylcholine pool size in human neonates with congenital diaphragmatic hernia requiring ECMO. J Pediatr. 2003;142:247-252.

43. Boucherat O, Benachi A, Chailley-Heu B, et al. Surfactant maturation is not delayed in human fetuses with diaphragmatic hernia. PLoS Med. 2007; 4:e237.

44. Van Meurs K. Is surfactant therapy beneficial in the treatment of the term newborn infant with congenital diaphragmatic hernia? J Pediatr. 2004;145:312316.

45. Lally KP, Lally PA, Langham MR, et al. Surfactant does not improve survival rate in preterm infants with congenital diaphragmatic hernia. J Pediatr Surg. 2004;39:829-833.

46. Pechkovsky DV, Hackett TL, An SS, et al. Human lung parenchyma but not proximal bronchi produces fibroblasts with enhanced TGF-beta signaling and alpha-SMA expression. Am J Respir Cell Mol Biol. 2010;43:641-651.

47. Bragg AD, Moses HL, Serra R. Signaling to the epithelium is not sufficient to mediate all of the effects of transforming growth factor beta and bone morphogenetic protein 4 on murine embryonic lung development. Mech Dev. 2001;109:13-26.

48. Chen H, Zhuang F, Liu Y-H, et al. TGF-beta receptor II in epithelia versus mesenchyme plays distinct roles in the developing lung. Eur Respir J. 2008;32:285-295.

49. Toiyama Y, Hur K, Tanaka K, et al. Serum miR-200c is a novel prognostic and metastasis-predictive biomarker in patients with colorectal cancer. Ann Surg. 2014;259:735-743

50. Valladares-Ayerbes M, Reboredo M, Medina-Villaamil V, et al. Circulating miR-200c as a diagnostic and prognostic biomarker for gastric cancer. J Transl Med. 2012;10:186.

51. Hu X, Macdonald DM, Huettner PC, et al. A miR-200 microRNA cluster as prognostic marker in advanced ovarian cancer. Gynecol Oncol. 2009;114:457464.

52. Ohuchida K, Mizumoto K, Lin C, et al. MicroRNA-10a is overexpressed in human pancreatic cancer and involved in its invasiveness partially via suppression of the HOXA1 gene. Ann Surg Oncol. 2012;19:2394-2402.

53. Santarpia L, Calin GA, Adam L, et al. A miRNA signature associated with human metastatic medullary thyroid carcinoma. Endocr Relat Cancer. 2013;20:809-823.

54. Köhler CU, Bryk O, Meier S, et al. Analyses in human urothelial cells identify methylation of miR-152, miR-200b and miR-10a genes as candidate bladder cancer biomarkers. Biochem Biophys Res Commun. 2013;438:48-53.

55. Gallot D, Boda C, Ughetto S, et al. Prenatal detection and outcome of congenital diaphragmatic hernia: a French registry-based study. Ultrasound Obstet Gynecol. 2007;29:276-283. 